\title{
Development of Ultrastructural Specializations During the Formation of Acetylcholine Receptor Aggregates on Cultured Myotubes
}

\author{
Anthony J. Olek, Alice Ling, and Mathew P. Daniels \\ Laboratory of Biochemical Genetics, National Heart, Lung, and Blood Institute, National Institutes of Health, \\ Bethesda, Maryland 20892
}

\begin{abstract}
The ultrastructure of cultured rat myotubes was examined at stages in the initial assembly of acetylcholine receptor (AChR) aggregates in order to elucidate the role of cell-surface specializations in aggregate formation. Within 4-6 hr, embryonic brain extract (EBX) induces the formation of sites of AChR density elevated 5-9 $\times$ above that of surrounding regions, and the appearance of these aggregates is preceded by the formation of clouds of punctate microaggregates (Olek et al., 1983). A video image-intensification system was used to monitor this redistribution of fluorescently labeled $\mathrm{AChR}$, and sites of aggregation were mapped on identified myotubes. After processing the cultures for electron microscopy, thin sections were taken through identified aggregate sites at various stages in assembly. Specializations, including a basal lamina, mound-shaped plasma membrane contours with occasional deep infoldings, and a subjacent dense cytoskeletal specialization, which tended to exclude other cytoplasmic organelles, were associated with newly formed aggregates found 4-6 hr after adding EBX to the cultures. Analysis of random thin sections through EBX-treated and untreated myotubes showed that the extent of specializations of the basal lamina and cytoplasm was approximately threefold greater in cells exposed to EBX for $4 \mathrm{hr}$, suggesting a concurrent, and possibly interdependent, organization of such specializations with AChR aggregate assembly. Examination of sections through clouds of microaggregates, which formed within $90 \mathrm{~min}$, revealed mound-shaped plasma membrane contours and underlying cytoplasm depleted of organelles but relatively little basal lamina and submembrane cytoskeletal density. These results suggest that the initial stage of $A C h R$ aggregate assembly involves relatively subtle changes in the structure of the cell cortex and that the evolution of microaggregates to aggregates may require the formation of additional cytoskeletal and extracellular matrix structures.
\end{abstract}

A critical question in cellular neurobiology is how certain regions within neurons and their synaptic targets become organized to subserve specialized functions. A striking example of such a region is the motor endplate, where a small area (less than $0.01 \%$ of the cell surface) of the muscle cell becomes highly differentiated in function and structure during synapse formation. While the function of the mature motor endplate in neuromuscular transmission has been well studied, relatively little

\footnotetext{
Received May 20, 1985; revised July 29, 1985; accepted July 31, 1985.

We would like to acknowledge Christina Kuo and Li Shyu for their technical help, Shirley Rothlein and Imogene Surrey for help with the manuscript, and Drs. Philip Nelson and Robert Bloch for their comments on the manuscript. A. Olek was recipient of a postdoctoral fellowship from the Muscular Dystrophy Association of America.

Correspondence should be addressed to Anthony J. Olek, Zoology Department, University of Maryland, College Park, MD 20742.

$0270-6474 / 86 / 020487-11 \$ 02.00 / 0$
}

is known about the development and maintenance of this structure and its other functional roles. The structural specializations of the postsynaptic muscle cell surface include a selectively enriched basal lamina (Bennett and Pettigrew, 1974; Coteaux, 1955; Sanes and Hall, 1979), folded plasma membrane containing a high density of AChRs (Daniels and Vogel, 1975; Fertuck and Salpeter, 1974), and an accumulation of cytoskeletal elements apposed to the membrane (Bloch and Hall, 1983; Ellisman et al., 1976; Froehner et al., 1981; Hall et al., 1981; Hirokawa and Heuser, 1982). Clearly, some elements of this structure, for example AChR and AChE, serve to mediate synaptic transmission, but the complete role of these specializations in cellular function and cell-cell interaction is unknown.

A number of studies have shown that structures resembling those at the neuromuscular junction can form at AChR-rich regions (AChR aggregates) on muscle cells in culture (Burrage and Lentz, 1981; Peng and Cheng, 1982; Salpeter et al., 1982; Sanes et al., 1984). However, very little is known about the functional role of these structures in the aggregation of AChRs. As one step in understanding this role, it is important to determine the precise relationship of the time course of assembly of these structures to the formation of AChR aggregates. To accomplish this, we have examined the ultrastructural changes that occur during the initial induction of $\mathrm{AChR}$-rich endplatelike structures in cultured rat myotubes by a soluble brain extract (Olek et al., 1983; Salpeter et al., 1982; Sanes et al., 1984). In order to study the spatial and temporal relationships precisely, we have directly monitored the induced aggregation of fluorescently labeled AChR, using low incident illumination and a video image-intensification system to eliminate the inhibitory effect of illumination on the aggregation of fluorescently labeled AChR (Olek et al., 1983). The associated ultrastructure at stages within the first $6 \mathrm{hr}$ of AChR aggregate formation was subsequently examined on the same, directly monitored myotubes. In addition, the ultrastructure of myotubes exposed to EBX for $4 \mathrm{hr}$ was compared with that of untreated control cells. The results indicate that the first detectable stage of $A C h R$ aggregate assembly, the formation of clouds of microaggregates (Olek et al., 1983), is associated with relatively subtle changes in the cellsurface contour and underlying cytoskeleton. The extensive appearance of a distinct basal lamina and a co-extensive dense cytoplasmic specialization, as well as deeper folds in the myotube surface, appears to occur after microaggregate assembly but is closely correlated with the initial formation of AChR aggregates per se.

\section{Materials and Methods}

\section{Cell cultures}

Cultures of dissociated muscle cells from the hind limbs of 19-21 d embryonic Sprague-Dawley rats were prepared essentially as described 

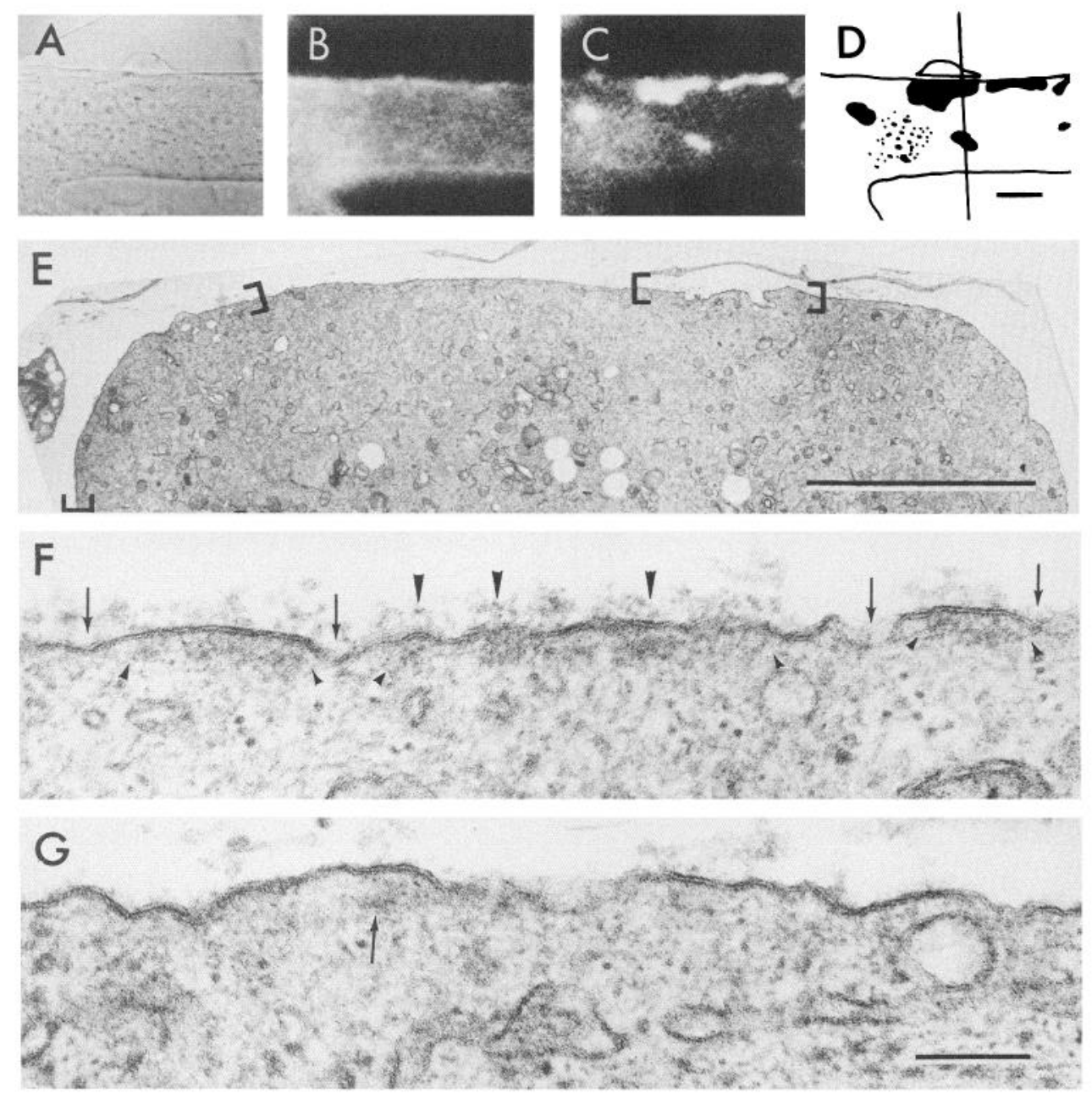

Figure 1. Phase contrast $(A)$, fluorescence $(B, C)$, and electron micrographs $(E-G)$ from a cultured myotube. Cells were preincubated with TMRBTX to label AChR, photographed with the video intensification system $(B)$ and then exposed to EBX. After 4 hr the same cell was rephotographed $(C)$ and the culture fixed and processed for electron microscopy. Within $4 \mathrm{hr}$ many aggregates developed $(C)$ on the top and edge (as determined in a through focus series) surfaces from an initially diffuse distribution of $\mathrm{AChR}(B)$. The position of fluorescently identified aggregates was mapped as represented $(D)$, and a thin cross section was taken through aggregate and nonaggregate regions as indicated (vertical line in $D)$. A low magnification EM montage through the top half of the cell was assembled $(E)$. The positions of mapped aggregate regions are shown (brackets). Note the presence of a damaged cell on the left-hand edge of the myotube as a landmark. Medium magnification electron micrographs from a neighboring section through the designated aggregate site $(F)$ on the left edge of the myotube and a nonaggregate site $(G)$ at top center are shown. At the aggregate site, basal lamina is concentrated outside the plasma membrane, the plasma membrane is "scalloped" (two regions between arrows), and there is an apposed cytoplasmic density (between small arrowheads). A lamellar organization of the cytoplasmic density, with a deeper zone of relatively high density, is apparent at most sites (exception, middle large arrowhead, where the plasma membrane is not cut transversely). Occasionally, cytoplasmic densities and basal lamina are seen apposed to plasma membrane with less regular contours (large arrowheads). In contrast, little or no basal lamina is present at the nonaggregate site, the plasma membrane is irregular in contour, and only a small cytoplasmic density is evident (arrow). Calibration bars: $A-D, 10 \mu \mathrm{m} ; E, 5 \mu \mathrm{m} ; F$ and $G, 0.2 \mu \mathrm{m}$. Magnification: $A-D, 560 \times ; E, 5600 \times ; F$ and $G, 68,100 \times$.

(Schaffner and Daniels, 1982). Cells were plated on carbon and collagen coated no. 1 glass coverslips at a density of $6 \times 10^{5}-8 \times 10^{5 / 35} \mathrm{~mm}$ plastic dish. Cells were grown in $80 \%$ Dulbecco's Modified Eagles Medium (DMEM), 10\% fetal calf serum, and 10\% heat-inactivated horse serum. After 4-5 d the cultures were fed with $90 \%$ DMEM, $10 \%$ horse serum, $5.4 \mu \mathrm{M}$ fluorodeoxyuridine and $13.2 \mu \mathrm{M}$ uridine to reduce the background of nonmuscle cells. After 1 additional day, the cultures were fed with $90 \%$ DMEM, $10 \%$ horse serum containing $1.5 \mu \mathrm{M}$ tetrodotoxin to prevent myotube contraction and were fed with the same medium every $3 \mathrm{~d}$ thereafter. Cultures were used $7-10 \mathrm{~d}$ after plating.

To label AChR, cells were incubated in $100 \mathrm{~nm}$ tetramethylrhodamine-conjugated $\alpha$-bungarotoxin (TMR-BTX) in DMEM containing 2 $\mathrm{mg} / \mathrm{ml}$ bovine serum albumin, $1.5 \mu \mathrm{M}$ tetrodotoxin, and $50 \mu \mathrm{g} / \mathrm{ml}$ of penicillin and streptomycin, buffered to $\mathrm{pH} 7.2$ with n-2-hydroxyethylpiperazine- $N$-2-ethane sulfonic acid (HEPES) for $1 \mathrm{hr}$, followed by three $10 \mathrm{~min}$ washes to remove unbound toxin. TMR-BTX was prepared essentially as described (Ravdin and Axelrod, 1977). In some experi- ments, a mixture of TMR-BTX and HRP-conjugated $\alpha$-bungarotoxin (HRP-BTX) was used to label AChR for light and electron microscopy. For the initial mapping of AChR aggregates, cells were incubated in 600 nм HRP-BTX and $100 \mathrm{~nm}$ TMR-BTX. For later studies mapping microaggregates and aggregates, $400 \mathrm{nM}$ HRP-BTX and $100 \mathrm{nM}$ TMRBTX were used. HRP-BTX was prepared by Drs. Z. Vogel and M. Towbin as described (Vogel et al., 1979).

\section{Video microscopy}

For purposes of this study, an AChR aggregate was defined as a brightly fluorescent patch on myotubes prelabeled with TMR-BTX, distinct from the background, longer than $2 \mu \mathrm{m}$ in greatest dimension and irregular in shape. After $4 \mathrm{hr}$ exposure to EBX, approximately $8-10 \%$ of the top half of responsive myotubes became occupied by aggregates, with the mean area of aggregates being $12 \mu \mathrm{m}^{2}$ (see Fig. 1; Olek et al., 1983).

Coverslip cultures were prelabeled with TMR-BTX and maintained at $35-37^{\circ} \mathrm{C}$ in a perfusion chamber. At various times after the addition 
of EBX, identified myotubes were photographed using a video imageintensification system, under reduced illumination, to monitor the assembly of AChR aggregates (see Olek et al., 1983). To summarize: Cells were examined with a Zeiss photomicroscope II equipped for epifluorescence with a $50 \mathrm{~W}$ mercury lamp and a $63 \times$ n.a. 1.4 lens. Images were generated by either a silicon-intensified target camera (RCA, Lancaster, PA) or a Venus low-light-level camera (Zeiss, Baltimore Instruments, Baltimore, MD) and photographed from a Hitachi or Lenco video monitor. For each time series, cells were exposed to less than 5 $\mathrm{sec}$ of total fluorescence illumination, with the intensity reduced by placing a 0.12 or 0.06 transmittance neutral density filter in the excitation beam pathway. Transmitted light for phase-contrast photography was reduced by a red filter and a 0.12 transmittance neutral density filter.

\section{Electron microscopy}

After the last series of phase contrast and fluorescence photographs, the temperature was reduced to less than $26^{\circ} \mathrm{C}$ to inhibit further aggregation (Olek, unpublished observations). Photographs were taken at low magnification $(100 \times)$ to aid in relocation of cells. Cultures were fixed in $2.5 \%$ glutaraldehyde with 0.25 or $0.15 \%$ tannic acid in $0.12 \mathrm{M} \mathrm{Na}$ cacodylate buffer, $\mathrm{pH} 7.0-7.2$ (final), for $30 \mathrm{~min}$ at room temperature, then $60 \mathrm{~min}$ at $4-10^{\circ} \mathrm{C}$. Cells were postfixed for $1 \mathrm{hr}$ in $1 \% \mathrm{OsO}_{4}$ in the same buffer, stained en bloc (Karnovsky, 1967) with $4 \%$ uranyl acetate in $0.06 \mathrm{M}$ maleate buffer, $\mathrm{pH} 5$, for $90 \mathrm{~min}$ at $4-10^{\circ} \mathrm{C}$, dehydrated in an ethanol series, and embedded in Epon 812.

When a mixture of TMR-BTX and HRP-BTX was used to label AChRs, coverslip cultures were rinsed after glutaraldehyde fixation with $0.12 \mathrm{M} \mathrm{Na}$-cacodylate buffer and $0.05 \mathrm{M}$ Tris buffer, $\mathrm{pH} 7.6$, and incubated for 40 or $30 \mathrm{~min}$ (for minimum reaction) at room temperature in $0.16 \mathrm{mg} / \mathrm{ml} \mathrm{2,2}$-diaminobenzidine (DAB) with $0.003 \% \mathrm{H}_{2} \mathrm{O}_{2}$ in the dark. The cultures were then rinsed in Tris buffer and Na-cacodylate buffer and processed as described above.

After embedding with Epon, the coverslip was removed from cultures and identified myotubes were relocated. From phase-contrast and fluorescence photomicrographs the location of AChR aggregate regions was mapped, and serial and semiserial transverse thin sections were taken through such selected regions. By using distinct features of the culture as landmarks (e.g., bifurcation of cells, location of cell nuclei and nucleoli), aggregate regions larger than $1 \mu \mathrm{m}$ could be routinely mapped. In experiments where AChR were labeled with both TMRBTX and HRP-BTX, the precision of the mapping procedure was confirmed by plotting the coincidence of HRP reaction product at the electron-microscopic level with maps of aggregate regions generated from fluorescence micrographs (see Fig. 5, for example). Thick sections, approximately $0.5 \mu \mathrm{m}$, were initially taken, stained with $0.05 \%$ toluidine blue and observed to locate the general region of interest. Thin sections, approximately $50-100 \mathrm{~nm}$, were subsequently cut and stained with uranyl acetate and lead citrate for examination. In experiments employing HRP mapping, some sections were left unstained to achieve optimal location of DAB reaction product. Montages of the identified cells were made at $45,000 \times$ final magnification for mapping purposes, and micrographs at higher magnification were taken at regions of interest. From the phase-contrast and fluorescence micrographs, AChR aggregate regions were identified in the montage of the myotube at $45,000 \times$ magnification (see Fig. 1, for example).

\section{Quantitative assay of specializations in electron micrographs}

To assess the extent of basal lamina and cytoplasmic specialization at $\mathrm{AChR}$ aggregate regions, montages of the top half of myotubes were made as described at 45,000 $\times$ final magnification. A zone $100 \mathrm{~nm}$ about the plasma membrane was examined for the presence of basement membrane and cytoplasmic specialization by a trained but experimentally naive analyst. A map of AChR aggregate regions was later transposed to the montage, and the extent of coincidence between regions of specialized structure and the AChR aggregate map was calculated and normalized to a unit length of the cell perimeter. A specialization was considered discrete if separated from another distinct specialization by $50 \mathrm{~nm}$.

For calculating the extent of specializations in random sections through control and EBX-treated myotubes, a similar procedure was employed, except the extent of specialization was simply measured and normalized to the cell perimeter. A similar procedure was employed to measure specializations in cells mapped with HRP-BTX, except that specializations were normalized to unit length of HRP-positive membrane.

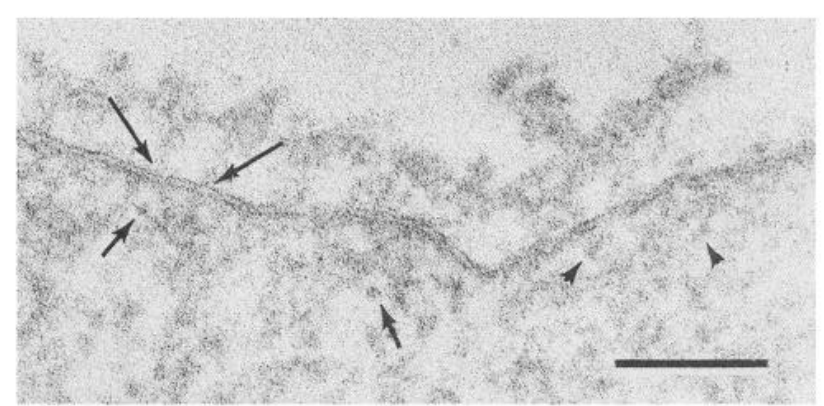

Figure 2. High-magnification electron micrograph from a tilt series of a thin section through a newly formed $(6 \mathrm{hr})$ AChR aggregate site. The AChR aggregate site was mapped as illustrated in Figure 1 and the entire area shown is within an AChR aggregate site. The basal lamina is treelike in appearance, with greatest electron density approximately $30-100$ $\mathrm{nm}$ from the membrane (lamina densa) and the "trunk" frequently aligned (long arrows) with filaments at the cytoplasmic face of the plasma membrane. Some rounded profiles in the cytoplasmic specialization (short arrows) largely maintained their appearance through a total tilt of $90^{\circ}$, indicating a globular nature. Other such profiles could be seen to elongate (arrowheads), indicating a rod-like or filamentous nature. Calibration bar, $0.1 \mu \mathrm{m}$. Magnification: $150,180 \times$.

\section{Results}

\section{Ultrastructure at newly formed AChR aggregate sites}

For purposes of this study, an AChR aggregate was defined as a brightly fluorescent patch on myotubes prelabeled with TMRBTX, distinct from the background, longer than $2 \mu \mathrm{m}$ in greatest dimension, and irregular in shape (see Methods; Fig. 1).

After mapping aggregates that had formed within 4-6 hr, a number of semiserial and serial sections through 15 aggregate and nonaggregate sites from seven different cells were examined. A characteristic structure (of aggregate in contrast to nonaggregate regions) was evident at all sites examined.

The basal lamina (Figs. 1-4) was concentrated at these sites, extending approximately $100 \mathrm{~nm}$ from the plasma membrane. In contrast, basal lamina was present only sparsely at most nonaggregate regions (Fig. 1). The basal lamina was most electron dense $30-100 \mathrm{~nm}$ from the plasma membrane, with wispy material crossing the intervening space, often lending the appearance of a tree-like structure to the lamina (Fig. 2). This wispy material was often found at sites where cytoplasmic structures closely apposed the plasma membrane (Fig. 2). In serial sections, the basal lamina was found to be concentrated over plasma membrane mounds within an AChR aggregate site (see below); however, basal lamina often "bridged" the intermound regions (Fig. 3).

The cytoplasmic region at aggregate sites was also highly differentiated, especially in a zone $50-100 \mathrm{~nm}$ from the plasma membrane. This zone was primarily composed of filamentous and particulate material, most densely packed within $20-50 \mathrm{~nm}$ from the membrane, and containing a mixture of 4-10-nm-thick fibrils and granules. A zone immediately beneath the membranes was relatively electron lucent, largely containing finer filaments 4-6 nm in thickness (Figs. 1-3). The region of cytoplasmic specialization generally excluded membranous organelles and myofibrils that often could be found approaching the plasma membrane in nonaggregate regions, although membranous vesicles or tubules were often found at the "notches" between plasma membrane mounds, sometimes in continuity with the plasma membrane (Figs. 3 and 4). In serial sections, individual punctate profiles within the cytoplasmic specialization could be traced running perpendicular through four or five thin sections (approximately $400 \mathrm{~nm}$ ), suggesting that some of these elements might in fact be filamentous (Fig. 3). Other profiles 

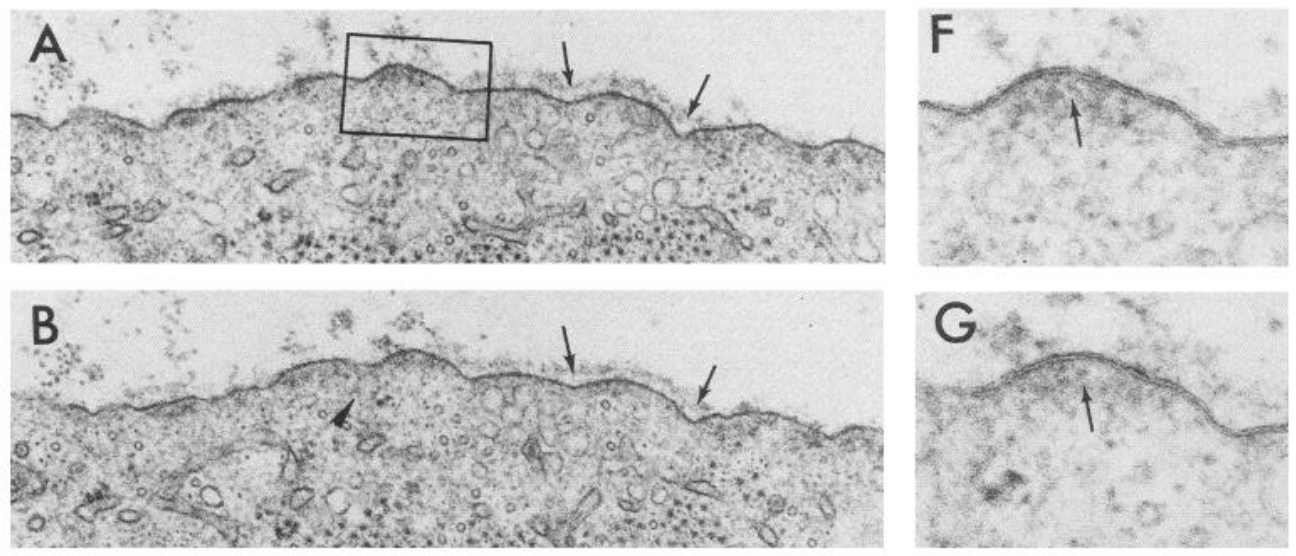

Figure 3. Electron micrographs of transverse serial sections from a region contained within a $6 \mathrm{hr} \mathrm{AChR}$ aggregate site on a cultured myotube. A series at intermediate magnification is shown $(A-E)$ and the indicated selected area (box in $A$ ) is depicted at higher magnification $(F-J)$. The aggregate site is characterized by plasma membrane mounds (example between arrows), which can be seen to disappear or branch in the series. Basal lamina is highly associated with the aggregate site but not present over all mounds. Most mound regions are subtended by cytoplasmic densities that exclude other structures. Membranous organelles can be found approaching the membrane between mounds (arrowheads, $B-E$ ). In the zone of cytoplasmic specialization, small dense profiles can be traced through five or more sections (for example, arrows, $F-J$ ), suggesting the presence of filaments or rods. Calibration bars: $A-E, 0.5 \mu \mathrm{m} ; F-J, 0.1$ $\mu \mathrm{m}$. Magnification: $A-E, 32,300 \times ; F-$ $J, 81,000 \times$.
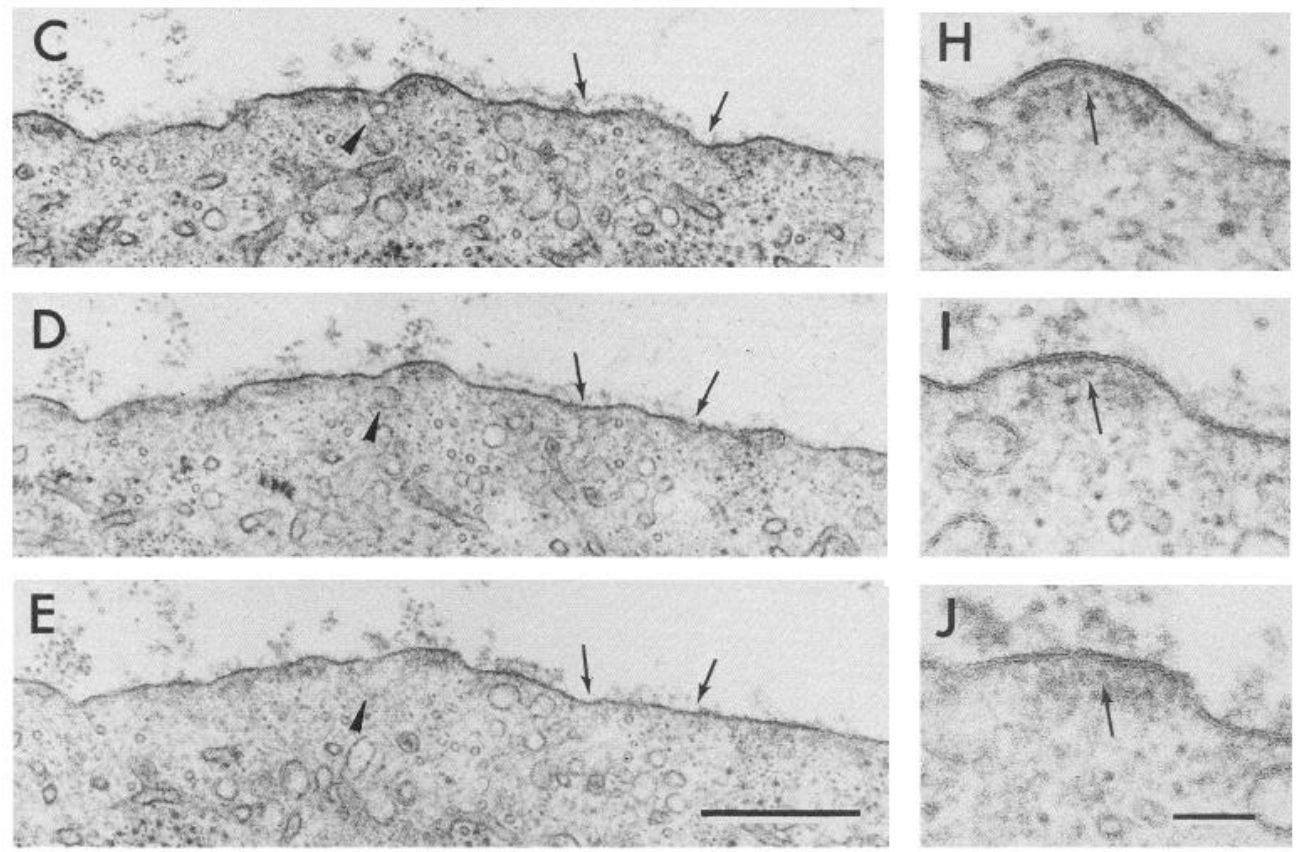

appeared by this analysis to be globular granules or short rods. By taking EMs of a single section tilted through $90^{\circ}$, the apparent filamentous nature of some elements was confirmed, while other elements were shown to be globular or particulate. In addition, tilting of sections more clearly revealed the association of cytoplasmic filaments and basal lamina extensions with the plasma membrane (Fig. 2; tilt series not shown).

The contour of the plasma membrane was also specialized at aggregate sites relative to nonaggregate regions. The membrane showed a predominantly "scalloped" contour with somewhat irregular raised or mound-like structures apparent in single thin sections (Figs. 1 and 3-5). These scallops ranged in length from approximately 0.2 to $1.5 \mu \mathrm{m}$, with a maximum length-to-height ratio of approximately 5:1. From an analysis of serial sections through an AChR aggregate site, the plasma membrane scallops were found to be part of irregular, mound-like, sometimes branched, structures, so that aggregate region consisted of closely packed raised islands on the cell surface (Fig. 3; and see model, Fig. 7). The analysis suggested that most of the mounds were not long ridges. Cytoplasmic specializations were generally confined to regions underneath the mounds. Deeper invaginations of the plasma membrane were sometimes seen (Figs. 1E, and 4) at compact, fluorescently bright aggregate sites. In these regions, basal lamina and cytoplasmic specializations were associated with almost the entire length of the folded plasma membrane.
In contrast to aggregate sites, no characteristic features of the membrane topography were evident at nonaggregate regions, although the membrane at such sites often demonstrated small irregular ripples (Fig. 1).

To assess the quantitative concentration of basal lamina and cytoplasmic specializations at newly formed aggregate sites, the extent of such specialization (described above) was measured at mapped sites and normalized to the top half of the myotube perimeter (see Methods) and compared with that found at nonaggregate sites. Measurements were made from at least three reconstructions of the top cell surface from nearby but not adjacent sections through a given aggregate and corresponding nonaggregate site. Ten aggregate/nonaggregate sites on five cells were evaluated in this way. A greater than 5-fold enrichment of basal lamina was found at aggregate sites, and similarly, almost a 4-fold enrichment of cytoplasmic specialization was evident (Table 1). Although the specializations were highly concentrated at aggregate sites relative to nonaggregate sites, only $50-60 \%$ of the plasma membrane at a mapped aggregate site was associated with clearly identified specializations (Table 1); however, this value may be an underestimation (see Discussion). The specializations were found to be evenly distributed within an aggregate site, not clustered in the center or at the edge of the aggregate site. There was a high degree of association between the presence of basal lamina and the presence of cytoplasmic specialization within an aggregate site; approximately 
$56 \%$ (length/length) of discrete basal lamina patches were associated with specializations apposed to the cytoplasmic face of the plasma membrane. Conversely, $85 \%$ of cytoplasmic specializations were associated with basal lamina (Table 1).

In the aforementioned studies, myotubes were prelabeled with TMR-BTX in order to observe new formation of aggregates, and the ultrastructure at such aggregate sites was examined 4$6 \mathrm{hr}$ later. To preclude an effect of prolonged ligand occupancy of AChR on the associated ultrastructure, some cultures of myotubes were postlabeled with TMR-BTX after $4 \mathrm{hr}$ in EBX, and sections were taken through large aggregates that developed on the top surface of cells as previously described. The principal features characteristic of prelabeled aggregate sites were also apparent on postlabeled cells: concentrated basal lamina, scalloped plasma membrane, and cytoplasmic specialization.

\section{HRP-mapped aggregates}

The aforementioned observations were drawn from EMs through AChR aggregate sites using light-microscopic mapping techniques. The precision of this mapping procedure was confirmed using a mixture of TMR-BTX and HRP-BTX to label AChR both at the light- and electron-microscopic level. Maps of fluorescently identified AChR aggregates $(n=11$, from 5 myotubes) on the cell surface coincided well with areas having dense deposits of DAB reaction product in electron micrographs (see Fig. 5, for example). The size of a fluorescently identified aggregate region agreed reasonably well (within $15 \%$ ) with the extent of corresponding HRP-positive membrane. The borders of HRP-positive membrane sites were sharp, in correlation with the appearance of fluorescently identified aggregates. The projected center of an aggregate map on an electron-microscopic reconstruction was within $10 \%$ of the center of an HRP-positive membrane site. The HRP-BTX technique, although useful in

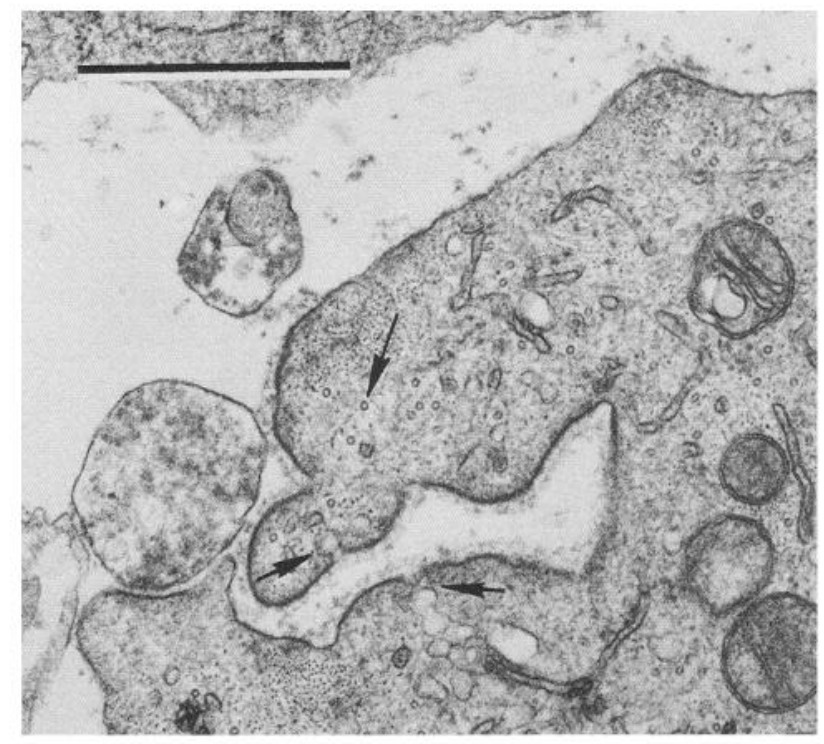

Figure 4. Electron micrograph of a cross section within a newly formed ( $4 \mathrm{hr}$ ) AChR aggregate site on a cultured myotube. The AChR aggregate site was mapped as illustrated in Figure 1. A deep invagination of the plasma membrane is shown. Both basal lamina and cytoplasmic specializations are evident virtually throughout the length of the folded membrane. Plasma membrane mounds also are evident within the folded regions. Microtubules are abundant within the folds (example, long arrow). Note continuity of plasma membrane vesicles and tubules (short arrows) with notches between mounds. Calibration bar, $1 \mu \mathrm{m}$. Magnification: $25,000 \times$.
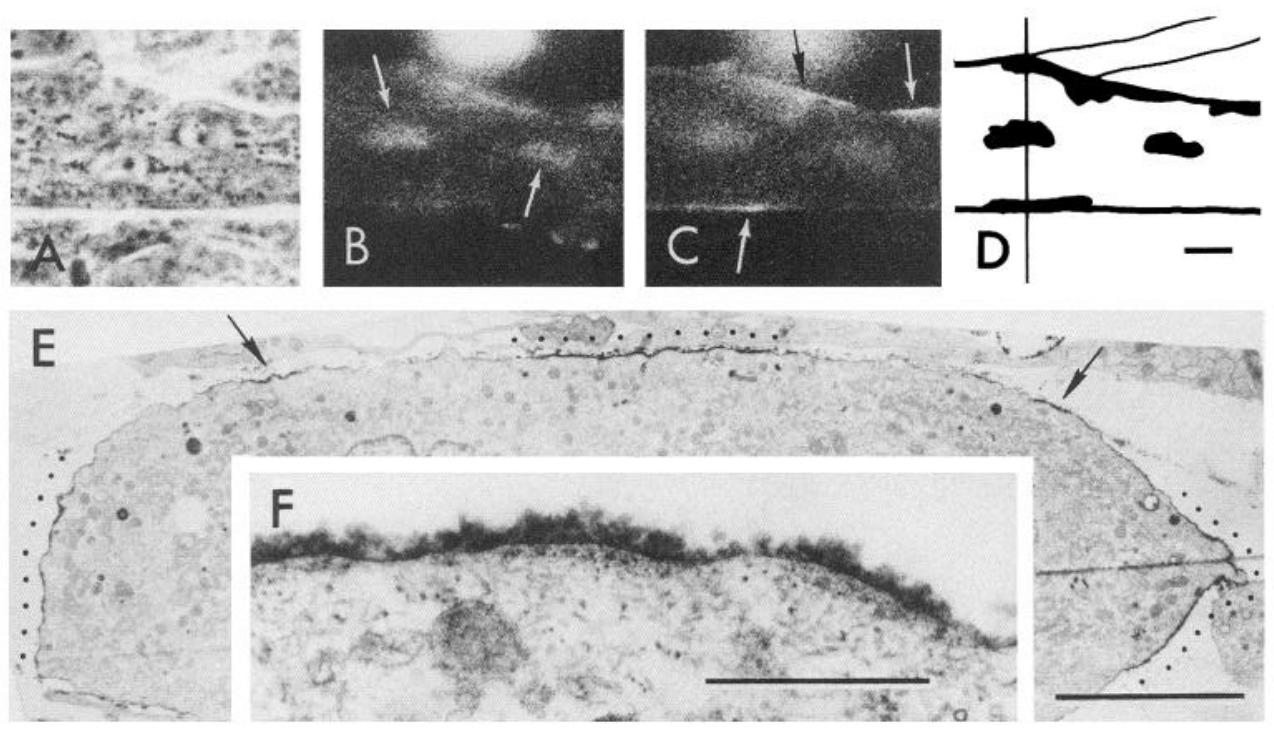

Figure 5. Phase contrast $(A)$, fluorescence $(B, C)$, and electron micrographs $(E, F)$ of a cultured myotube. AChR were labeled with a mixture of TMR-BTX and HRP-BTX for sequential light- and electron-microscopic examination. In this study, the mixture was adjusted (see Methods) to favor binding of HRP-BTX, so that the fluorescence was reduced. Cells were exposed to EBX for $4 \mathrm{hr}$, fluorescence photographs taken, and then the cultures fixed and processed for electron microscopy. AChR aggregates (arrows) were present on the top of the cell (in focus in $B$ ) and on the edges of the cell (in focus in $C$ ). A thin cross section was taken through the designated level, including the top and edge aggregate sites, as shown on the map $(D)$. In the montage reconstruction of the top half of the cell, the projected map (from fluorescence photographs) of elevated AChR density is indicated (dots). These regions corresponded well with regions of elevated DAB reaction product (dark granules indicating bound HRP$B T X)$. Some small $(<1 \mu \mathrm{m})$ patches of HRP-positive membrane did not correspond with the fluorescence map (arrows, E). Shown at higher magnification $(F)$ is a selected region of the large top aggregate site in $E$, taken from a neighboring thin section. Plasma membrane mounds and cytoplasmic specializations are apparent, but the cytoplasmic specializations appear more granular than in material not processed to detect HRP. The DAB reaction product also accumulates in the lamina lucida and stains the lamina densa under these conditions. Calibration bars: $A-D, 10$ $\mu \mathrm{m} ; E, 5 \mu \mathrm{m} ; F, 0.5 \mu \mathrm{m}$. Magnification: $A-D, 507 \times ; E, 3980 \times ; F, 45,400 \times$. 
Table 1. Extent of specializations ${ }^{a}$ at mapped $A C h R$ aggregate sites

\begin{tabular}{|c|c|c|}
\hline & $\begin{array}{l}\text { Aggregate } \\
\text { site } \\
(\text { mean } \pm 1 \mathrm{SD})\end{array}$ & $\begin{array}{l}\text { Nonaggregate } \\
\text { site } \\
\text { (mean } \pm 1 \mathrm{SD}\end{array}$ \\
\hline \multicolumn{3}{|l|}{$\%$ of Membrane associated with } \\
\hline Basal lamina & $45.5 \pm 6.7$ & $9.0 \pm 3.7$ \\
\hline Cytoplasmic specializations & $64.5 \pm 5.6$ & $17.6 \pm 4.4$ \\
\hline \multicolumn{3}{|l|}{$\%$ Coincidence } \\
\hline $\begin{array}{l}\text { Basal lamina with apposed } \\
\text { cytoplasmic specialization }\end{array}$ & $56.2 \pm 18.8$ & $41.0 \pm 15.2$ \\
\hline $\begin{array}{l}\text { Cytoplasmic specializations } \\
\text { with apposed basal lamina }\end{array}$ & $84.6 \pm 14.6$ & $64.1 \pm 17.1$ \\
\hline
\end{tabular}

${ }^{a}$ Specialization was defined as the presence of either basal lamina or cytoskeletal density within $100 \mathrm{~nm}$ of the plasma membrane.

locating AChR-rich membrane, obscured or altered some ultrastructural detail. The dense DAB reaction product at aggregate sites tended to accumulate at the cell surface, filling the lamina lucida of the basal lamina and staining the lamina densa. The cytoplasmic specializations apposed to HRP-positive membrane were noticeably different from those found at aggregate sites mapped with only fluorescence criteria (compare Figs. 2 and $5 F$ ); the filamentous material was not as apparent, and the submembrane density was more granular. It is possible that some of the DAB reaction product penetrated to the cytoplasm close to the membrane, or the reaction procedure otherwise altered the ultrastructure. However, a recognizable concentration of cytoplasmic specialization was still evident relative to that found at HRP-negative membrane sites. For these reasons the description of the ultrastructure at aggregate sites relied on the examination of fluorescently mapped regions whenever possible. Aggregates larger than $1 \mu \mathrm{m}$ could be confidently mapped in this way, and all aggregates examined in this study were larger than $2 \mu \mathrm{m}$ in smallest dimension. However, quantification of structures at such mapped sites could be subject to $10-15 \%$ error due to imprecise mapping. Further, it was expected that mapping of aggregates using fluorescence techniques would overestimate the actual area occupied by AChR-rich membrane, as substructure within an aggregate site was not considered, although it could be detected in fluorescence micrographs (Olek et al., 1983). Studies with HRP-BTX-labeled material confirmed that a site designated by fluorescence criteria as a single aggregate was actually a mosaic of closely packed AChR-rich membrane regions (data not shown).

\section{De novo appearance of specializations after exposure of myotubes to $\mathrm{EBX}$}

The structure that was found in association with AChR aggregate sites could exist prior to the formation of aggregates, and as such might organize the redistribution of AChR in response to EBX. To address this point, random thin cross sections were cut through EBX-treated and untreated myotubes. The extent of basal lamina and cytoplasmic specializations within $100 \mathrm{~nm}$ of the plasma membrane was evaluated and normalized to the cell perimeter (see Methods). There was approximately a 3-fold increase in the extent of both basal lamina and cytoplasmic specializations in EBX-treated myotubes (Table 2). A smaller increase was found in the number of discrete specializations pcr unit length of membrane. The principal difference between experimental and control cells was the larger average size of specializations in EBX-treated myotubes (Table 2). Discrete specializations were evenly distributed across the top half of cells in both EBX-trcatcd and untreated myotubes; there was no preferential location of specializations, i.e., at the edges or in
Table 2. Extent of specializations ${ }^{a}$ in random sections

\begin{tabular}{|c|c|c|}
\hline & $\begin{array}{l}\text { EBX-treated } \\
(n-14)\end{array}$ & $\begin{array}{l}\text { Untreated } \\
(n=11)\end{array}$ \\
\hline & \multicolumn{2}{|c|}{$($ mean $\pm S E)$} \\
\hline \multicolumn{3}{|c|}{$\%$ of Membrane length associated with } \\
\hline Basal lamina & $19.4 \pm 5.0$ & $6.4 \pm 3.0$ \\
\hline Cytoplasmic specialization & $16.4 \pm 4.0$ & $5.7 \pm 1.1$ \\
\hline \multicolumn{3}{|c|}{ Length of discrete ${ }^{b}$ specializations $(\mu \mathrm{m})$} \\
\hline Basal lamina & $0.61 \pm 0.14$ & $0.29 \pm 0.11$ \\
\hline Cytoplasmic specialization & $0.58 \pm 0.07$ & $0.26 \pm 0.04$ \\
\hline \multicolumn{3}{|c|}{ Number per length $(\mu \mathrm{m})$ of membrane } \\
\hline Basal lamina & $0.29 \pm 0.04$ & $0.22 \pm 0.02$ \\
\hline Cytoplasmic specialization & $0.29 \pm 0.03$ & $0.21 \pm 0.02$ \\
\hline \multicolumn{3}{|l|}{$\%$ Coincidence } \\
\hline $\begin{array}{l}\text { Basal lamina with apposed } \\
\text { cytoplasmic specialization }\end{array}$ & $74.2 \pm 4.6$ & $65.7 \pm 9.1$ \\
\hline $\begin{array}{l}\text { Cytoplasmic specialization } \\
\text { with apposed basal lamina }\end{array}$ & $60.8 \pm 4.4$ & $50.2 \pm 11.1$ \\
\hline
\end{tabular}

${ }^{a}$ Specialization was defined as the presence of either basal lamina or cytoskeletal density within $100 \mathrm{~nm}$ of the plasma membrane.

${ }^{b}$ Separated from other specializations by at least $50 \mathrm{~nm}$ along the plasma membrane.

the middle. However, discrete specializations in a given cross section were more clustered in EBX-treated myotubes.

\section{Early events in aggregate formation: ultrastructure at microaggregate cloud sites}

In order to examine the earliest stages of aggregate assembly detectable by our techniques, thin sections were taken through sites at the initial stages of aggregate formation that occurred between 0 and $2 \mathrm{hr}$ of EBX exposure. Previous studies (Olek et al., 1983) revealed that the earliest detectable step in aggregate formation was the development of clouds of microaggregates (approximately $1 \mu \mathrm{m}$ or less in diameter, with a punctate appearance). Because of the small size of the microaggregates, a mixture of TMR-BTX and HRP-BTX was employed in most studies to label AChR for location of microaggregates at the light- and electron-microscopic level. The microaggregate "cloud" site was located with fluorescence micrographs as previously described, and individual microaggregates were identified in electron micrographs as HRP-positive membrane regions. Concentrations of HRP-BTX and DAB reaction conditions were adjusted to limit the deposition of reaction product.

From semiserial and some serial sections through several microaggregate cloud sites (developing within $90 \mathrm{~min}$ of EBX application) on five different myotubes, a number of features were found to be characteristic of this stage of aggregation. Raised plasma membrane mounds, demonstrating elevated levels of $\mathrm{DAB}$ reaction product, were prominent within microaggregate cloud sites. These mounds showed a relatively homogeneous density of reaction product which dropped off sharply at the edges (Fig. 6). Measurements of the length of discrete (separated by more than $0.25 \mu \mathrm{m}$ ) HRP-positive membrane patches, as seen in thin sections, ranged from less than 0.2 to $1-2 \mu \mathrm{m}$. However, the most common patches ranged from 0.2 to $1.0 \mu \mathrm{m}$ and would be likely morphologic candidates for microaggregates as identified with fluorescence microscopy. Fluorescently mapped regions of diffuse $\mathrm{AChR}$ distribution (on the same cell demonstrating microaggregates) had few, if any, regions of elevated DAB reaction product or distinct plasma membrane mounds (Fig. 6).

Within a microaggregate cloud site, the cytoplasm approximately $100 \mathrm{~nm}$ beneath HRP-positive plasma membrane 

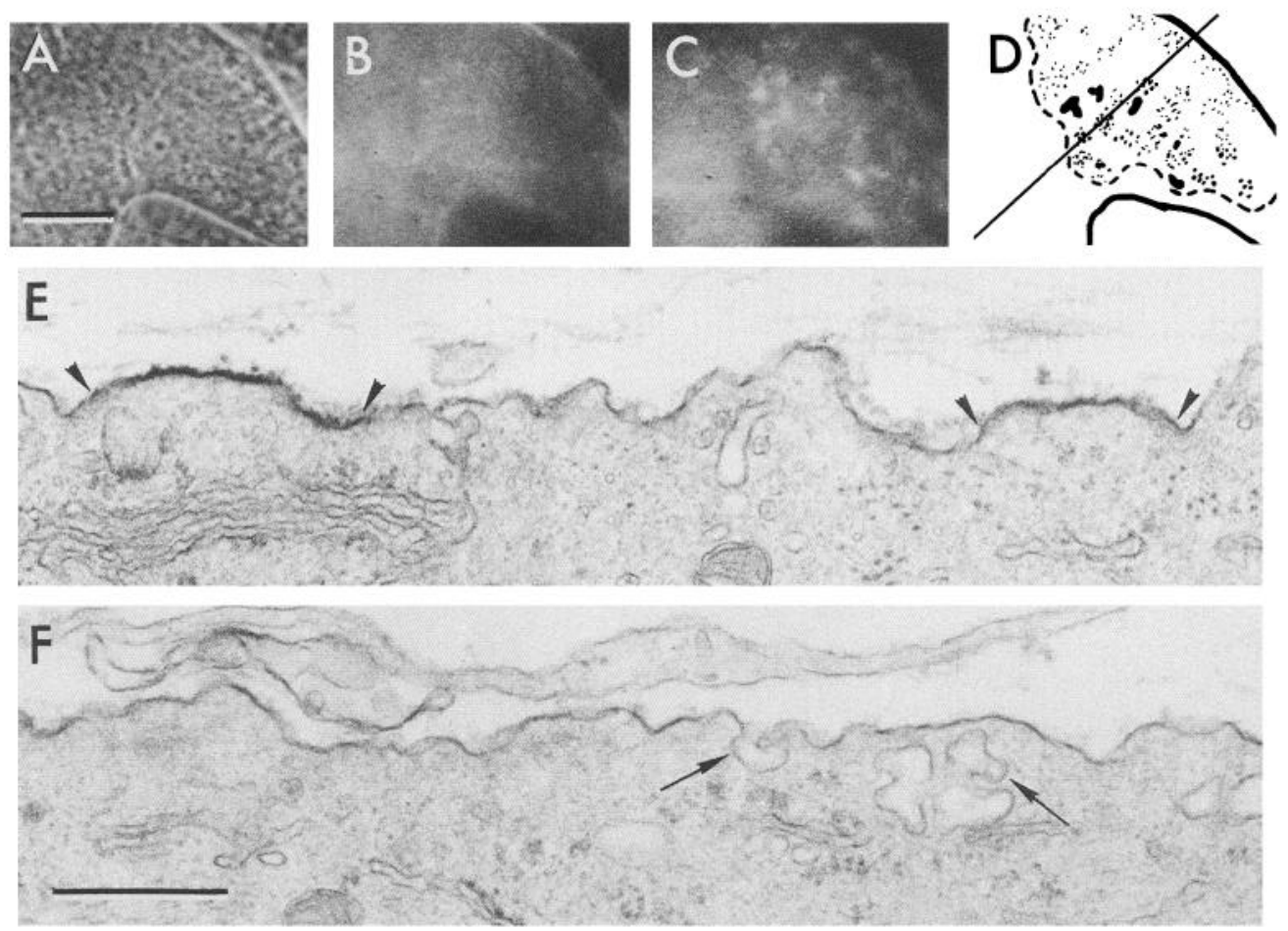

Figure 6. Phase contrast $(A)$, fluorescence $(B, C)$, and electron micrographs $(E-F)$ from a myotube exposed to EBX for 90 min. Cells were preincubated with a mixture of TMR-BTX and a minimum concentration of HRP-BTX to label AChR. The myotube was initially photographed with the video image intensification system $(B)$, exposed to EBX, rephotographed after $90 \mathrm{~min}(C)$, and then fixed and processed for detection of HRP-BTX and electron microscopy. The location of newly formed microaggregates (and some small aggregates, as defined by size) was mapped $(D)$, and a cross section was taken at the location indicated by the solid line $\pm 1 \mu \mathrm{m}$. The map was made using a through focus series at higher magnification. The groups of speckles and spots in the drawing represent the location of regions of elevated fluorescence (relative to that found initially) on the surface of myotubes. Panel $E$ was in part of the indicated microaggregate cloud region (within the dotted line) and $F$ in the region of relatively diffuse AChR distribution in the lower-left corner of the map. Regions of elevated DAB reaction product on plasma membrane mounds are indicated in panel $E$ (between arrowheads). The distribution of DAB reaction product was confirmed by examination of adjacent serial sections not stained with heavy metals. Notice vesicular-tubular membrane structures near and in continuity with the plasma membrane in $F$ (arrows). Calibration bars: $A-D, 10 \mu \mathrm{m} ; E-H, 0.5 \mu \mathrm{m}$. Magnification: $A-D, 459 \times ; E-H, 35,600 \times$.

mounds appeared to exclude membranous organelles and myofibrils, as was described for similar plasma membrane mounds found at "mature" aggregate sites (Fig. 6). Some basal lamina and cytoplasmic specializations were associated with HRP-positive membrane within a microaggregate cloud site. To determine the relative extent of such association, the lengths of basal lamina and cytoplasmic specializations were measured (see Methods) and normalized to unit length of HRP-positive membrane, both within microaggregate cloud sites and at more mature (4 hr EBX) aggregate sites on myotubes from sister cultures. Several sections from each of five microaggregate cloud sites from three cells, and six mature aggregate sites from two cells were evaluated. There was approximately 2 -fold less basal lamina and 3.5-fold less cytoplasmic specialization apposed to HRPpositive membrane within a microaggregate cloud site than at a mature aggregate site.

Within a microaggregate cloud site, larger regions (1-2 $\mu \mathrm{m})$ of HRP-positive membrane were often associated, over part of their extent, with both basal lamina and cytoplasmic specializations (not shown). It is likely that these larger reactive regions corresponded to the larger, brighter regions of fluorescence within the microaggregate cloud (Fig. 6). Small $(0.1-0.2 \mu \mathrm{m})$ patches of HRP-reactive membrane also were found within microaggregate cloud sites (not shown). Such structures would probably not be resolved with fluorescence microscopy but might correspond to elevated levels of fluorescence as seen over larger areas (see Fig. 6). These small patches were seldom associated with cytoplasmic specializations. At HRP-positive mounds within a microaggregate cloud site, a fine fibrillar material was evident subtending the mounds (Fig. 6), but it was not possible to determine in the present study whether this material was present at greater density at microaggregate mound sites than that subtending the cell surface elsewhere.

To confirm some general characteristics of microaggregate cloud sites without the possible interference of the DAB reaction, some cells were labeled with TMR-BTX alone and exposed to EBX for $90 \mathrm{~min}$ or $4 \mathrm{hr}$. The ultrastructure at microaggregate sites mapped by fluorescence was examined and compared with that found at mature aggregate sites. These microaggregate sites were characterized by the presence of plasma membrane mounds, and the mound sites appeared to be associated with less basal lamina and fewer cytoplasmic specializations than found at mature aggregate sites, in agreement with the results found with HRP-BTX labeling. However, quantification of such specialization was not made owing to lack of a precise map of microaggregate location under these conditions.

\section{Discussion}

On the basis of the findings reported here, we have formulated the following model of the ultrastructural development in the first 4-6 hr at the site of formation of an EBX-induced AChR aggregate (see Fig. 7). Within $2 \mathrm{hr}$ of EBX application at $36^{\circ} \mathrm{C}$, clusters, or "clouds" of plasma membrane mounds, $\leq 1 \mu \mathrm{m}$ in diameter, containing an elevated $\mathrm{AChR}$ site density, emerge from a more uniformly contoured plasma membrane with diffuse AChR. These microaggregate mounds are distributed sparsely within the cloud. There is relatively little basal lamina associated with microaggregate mounds or elsewhere on the cell 

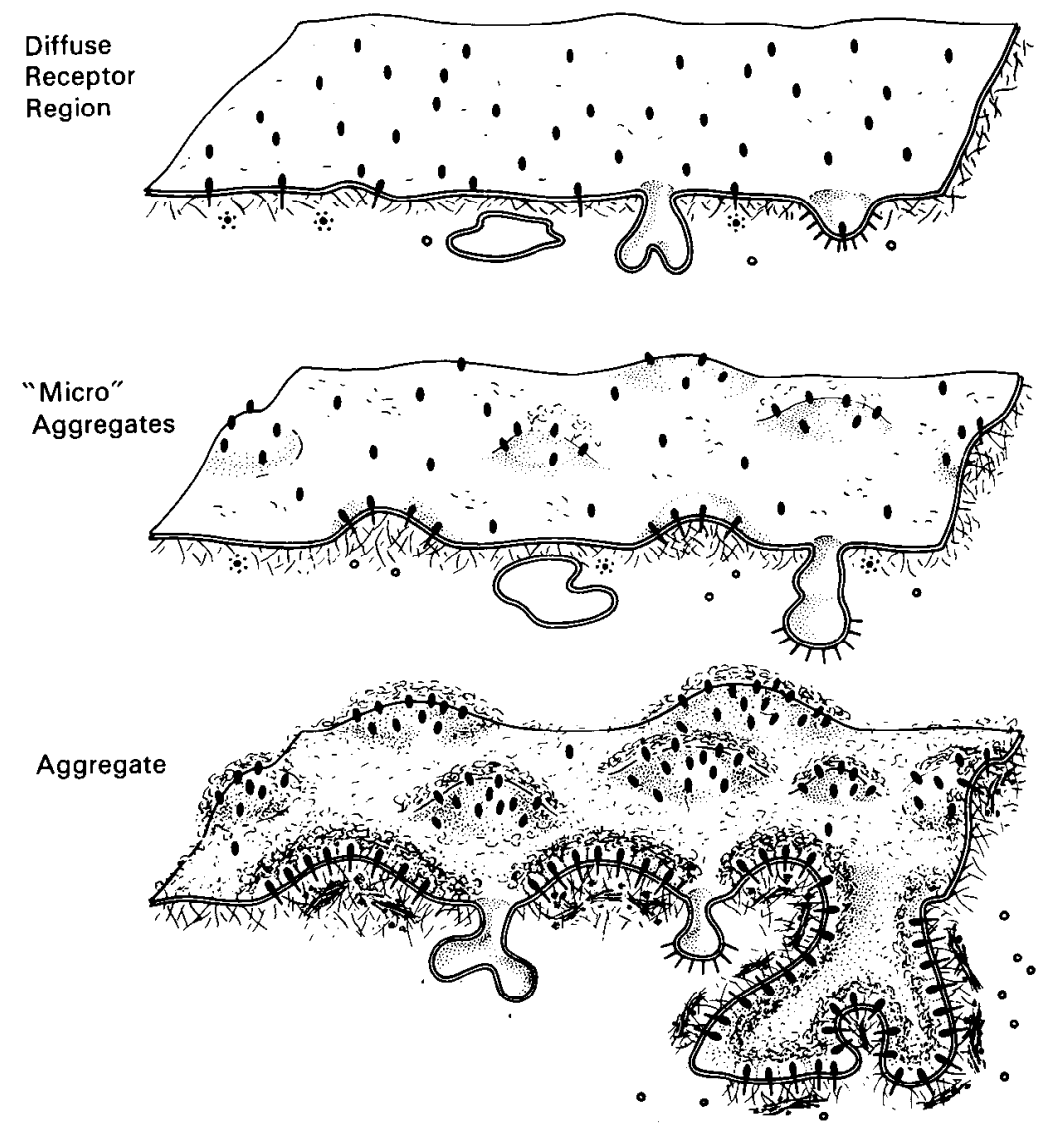

Figure 7. Model of the changes in structure of a cultured myotube surface region at the site of EBX-induced AChR aggregate development. Initially, AChR (dark ovoids) are diffusely distributed in the plasma membrane, and little basal lamina is present. The contour of the plasma membrane is not conspicuously organized, and the subjacent cytoplasm contains a relatively homogeneous cytoskeletal meshwork in which membranous organelles and myofibrils are frequently found. Within $90 \mathrm{~min}$ of EBX application, small (approximately $1 \mu \mathrm{m}$ or less) microaggregates of AChR appear, which are not highly associated with basal lamina. These sites of elevated AChR density are present at plasma membrane mounds, and the mounds are subtended by zones that appear to exclude membranous organelles and myofibrils. With time in the presence of EBX, larger (2-10 $\mu \mathrm{m}$ in greatest dimension) AChR aggregates develop, and these sites are highly associated with basal lamina. The plasma membrane mounds within the site are more closely packed, and AChR are present at higher density. Two zones of cytoplasmic specialization are found subtending the mounds. A relatively electron-lucent zone immediately subjacent to the membrane contains fine filaments spanning the gap from the membrane to a deeper zone. This deeper zone contains a coarser filamentous meshwork and some globular material. The cytoplasmic specialization appears to exclude membranous organelles and myofibrils, which can often be found at otherwise nonspecialized regions between the plasma membrane mounds. Deeper invaginations of the membrane, associated with specializations along almost the entire length, can sometimes be found within large aggregate sites, and microtubules are abundant in these folded regions.

surface. However, the cytoplasm immediately subjacent to these mounds has become specialized, being composed mainly of fine filaments that exclude organelles commonly associated with other regions of the membrane. With time, there is a transition from microaggregate to aggregate region in which a transmembrane complex, including basal lamina and a stratified cytoskeletal specialization, develops at the mounds. At the aggregate stage, these specialized mounds are closely packed, but somc intermound spacing is retained. The cytoplasmic intermound regions are often associated with tubular or vesicular structures. The nature of the transition from a relatively sparse cloud of microaggregate sites to a more compact, homogeneous, and specialized aggregate region is uncertain. However, it may involve the continuous formation of microaggregates to generate a closepacked state, as well as an increase of AChR density within microaggregates. Aggregate sites sometimes contain deep invaginations of the plasma membrane and the associated transmembrane complex with an accumulation of microtubules in the cytoplasm.

We feel that this model will provide a useful framework for understanding the initial structural development of the neuromuscular junction. In the remainder of the discussion we assess the validity of the findings on which the model was based and relate them to other observations on AChR aggregation, nervemuscle synapse formation, and the associated ultrastructural specialization found in culture and in vivo.

\section{Ultrastructure at the microaggregate cloud stage}

The most characteristic ultrastructural feature of microaggregate cloud sites was the presence of plasma membrane mounds with elevated AChR density. Our results indicate that AChR microaggregates can be confidently mapped on the ultrastructural level by the techniques used in this study. The relatively homogeneous distribution of $\mathrm{DAB}$ reaction product within the mounds and its sharp drop-off at the edges suggest that there was little diffusion artifact, if any, outside the mounds. In addition, although only a qualitative assessment of AChR density was made, there was a general correlation between the size and distribution of HRP-BTX positive mounds and punctate microaggregates seen by fluorescence microscopy using TMR-TBX. The mounds at microaggregate sites were similar in size and shape to those at mature aggregate sites, but they were fewer in number and not as closely packed. There was relatively little basal lamina and cytoplasmic specialization associated with mi- 
croaggregates; however, there was a fine fibrillar material subtending plasma membrane mounds and a paucity of cytoplasmic organelles. A meshwork of fine filaments, excluding most other organelles, has been described as an early feature of charged bead-induced AChR aggregate sites (Peng and Phelan, 1984).

\section{Structure at the aggregate stage}

At these newly formed aggregate sites was found a concentration of basal lamina, a plasma membrane specialized in contour and cytoplasmic structure. The basal lamina and cytoplasmic specializations were concentrated 5- and 4-fold, respectively, relative to nonaggregate regions in the same cell, suggesting a high degree of association between these specializations and AChR aggregate sites. Within an aggregate site the presence of basal lamina and cytoplasmic specialization were also highly associated with each other. Our mapping of AChR aggregate sites probably overestimated the actual extent of AChR-rich membrane within that site owing to our mapping technique and the likely existence of "substructure" within a fluorescently identified compact aggregate (see Cohen and Pumplin, 1979; Olek et al., 1983). Thus, the association of specialized structure with AChR-rich membrane may be even higher. This high degree of association between basal lamina, cytoplasmic specialization, and newly formed AChR aggregate sites is consistent with the idea that the development of these structures is interdependent. In addition to the statistical association between these structures, we frequently observed the alignment of cytoskeletal filaments with extracellular matrix structures traversing the lamina lucida. These results suggest the existence of a structural interaction that could be mediated by integral membrane proteins (see also Brown et al., 1983; Hay, 1982).

It is also likely that much of this structure is organized de novo, as evaluation of random sections through EBX-treated and untreated myotubes revealed that (within $4 \mathrm{hr}$ ) EBX induced at least a 3-fold increase in both basal lamina and cytoplasmic specialization. As would be expected if they were in association with AChR aggrcgatcs, thesc spccializations occurred with the same even distribution (that is, favoring neither center nor edges) across the top half of the myotubes (not on the bottom) and existed in clusters of approximately the same size range. Therefore, it is likely that the bulk of the basal lamina and cytoplasmic specializations are newly organized with the formation of aggregates. Certainly there were insufficient preexisting specializations (in untreated cells) to account for the extent of specialization found associated with identified aggregate sites (on cells exposed to EBX). However, it is possible that preexisting structures either with or without a high AChR site density might serve as organizing centers for subsequent development. In this regard, when examining the ultrastructure of myotubes labeled with both TMR-BTX and HRP-BTX, small patches of basal lamina and cytoplasmic specialization were sometimes found not in association with detectable (HRP-positive membrane) AChR aggregates (see also Burrage and Lentz, 1981; Salpeter et al., 1982).

The structures associated with newly formed aggregates are similar to some of the structures at the neuromuscular junction: distinct basal lamina, specialized plasma membrane, and subjacent cytoskeletal enrichment. In vivo, the basal lamina of rat muscle is present over the entire surface, with specialized components at the neuromuscular junction (Anderson and Fambrough, 1983; Sanes, 1982, 1983; Sanes and Hall, 1979). Previous studies have shown a similar induction of total basal lamina on cultured rat myotubes after treatment for a few days with a brain extract (Salpeter et al., 1982) and a specific increase in synaptic basal lamina antigens and AChE (Sanes et al., 1984). In addition, laminin has been found highly associated with brain extract-induced AChR aggregates (Daniels et al., 1984), and a heparan sulfate proteoglycan, as well as basal lamina, was se- lectively deposited at nerve-induced aggregates (Anderson and Fambrough, 1983; Anderson et al., 1984). In agreement with this result, basal lamina appears to form selectively at nervemuscle contacts in vitro (Nakajima et al, 1980; Weldon and Cohen, 1979). It is likely that brain extracts stimulate the deposition of extracellular matrix components onto the myotube surface. Consistent with this hypothesis, a brain extract treatment for $18 \mathrm{hr}$ has been shown to increase collagen synthesis in myotube cultures (Kalcheim et al., 1982). As the effect of EBX on basal lamina in the current study occurs rapidly (2-4 $\mathrm{hr}$, EBX-stimulated synthesis is not likely to be initially required. Rather, some other mechanism of selective deposition of basal lamina or rearrangement of surface basal lamina to the aggregate site is probable. Another possibility is that basal lamina is more firmly attached at the aggregate site, resisting removal during processing for electron microscopy. In any case, there must be some specialized interaction of basal lamina with the aggregate site.

Within $2 \mathrm{hr}$ of EBX application, mounds or raised ridges in the membrane are formed in association with AChR microaggregate clouds and aggregates; these mounds, while not uniform in size and configuration, were a characteristic feature of aggregate sites. Similar contours in cultured rat myotube membranes are evident in thin-section autoradiographs at sites of elevated ${ }^{125}$ I-BTX binding after treatment with a brain extract (Salpeter et al., 1982; see Fig. 5) and in association with HRP-BTX positive membrane in embryonic chick muscle in vivo and in vitro (Burrage and Lentz, 1981; Jacob and Lentz, 1979). In correlated fluorescence and freeze-fracture studies of cultured myotubes (Cohen and Pumplin, 1979; Peng and Cheng, 1982), it has been shown that the receptor aggregates consist of many small islands of elevated AChR (intramembranous particles) density, probably equivalent to that at the mounds described here. In the present study, deeper infoldings of the membrane were sometimes seen in association with larger, more compact aggregates showing brighter fluorescence. Sanes et al. (1984) report a large incrcase in folding of the cultured rat myotube membrane after a few days of brain extract exposure. It is likely that the membrane at aggregate sites becomes more extensively folded as the aggregate "evolves" (becoming more compact and increasing in AChR site density). However, the brain extract-induced infoldings described to date are different from the regular junctional folds found at the mature rat or mouse neuromuscular junction. At brain extract-induced folds, cytoplasmic specializations and elevated AChR density (the latter judged from HRP-BTX binding; A. J. Olek, A. Ling, and M. P. Daniels, unpublished observations) were present along almost the entire length of the folds at an aggregate site, while they are limited to the crests of the folds at the neuromuscular junction (Daniels and Vogel, 1975; Fertuck and Salpeter, 1974, 1976). Infolding of the membrane has also been found at sites of charged bead-induced AChR aggregation in cultured amphibian muscle (Peng and Cheng, 1982).

Much of the membrane region with high $\mathrm{AChR}$ density is associated with an enriched cytoskeletal structure. A submembrane density or "fuzz" has long been described at the neuromuscular junction (see Bennett and Pettigrew, 1974; Couteaux and Pecot-Dechavassine, 1968; Kelly and Zacks, 1969). More recently, the postsynaptic submembrane structure has been examined in more detail, and described as a filamentous network or "microtrabeculae" (Ellisman et al., 1976) and as a cytoskeletal complex including 4-10 nm filaments that might anchor the AChR to further underlying cytoskeleton (Hirokawa and Heuser, 1982). A filamentous enrichment subjacent to postsynaptic membranes in the central nervous system has also been described (see Gulley and Reese, 1981; Landis and Reese, 1983).

As has been shown in the present study, cytoplasmic specializations associated with newly formed AChR aggregates share 
some features with those seen underlying the membrane at the motor endplate. There is the presence of fine filaments, approximately $4-6 \mathrm{~nm}$ in diameter, found frequently in a meshwork within $20 \mathrm{~nm}$ from the plasma membrane. These filaments are often contiguous with a denser network approximately 20 $50 \mathrm{~nm}$ from the membrane containing 4-10 nm filaments and some particulate or short rodlike structures. This deeper specialized zone is a very characteristic feature of the cytoplasm subtending aggregate sites. An accumulation of dense material has been generally seen in the immediate (less than $20 \mathrm{~nm}$ ) submembrane cytoplasm at AChR-rich membrane: at mature neuromuscular junction (see above), developing neuromuscular junction (Kelly and Zacks, 1969), neurite-myotube contacts in culture (Nakajima et al., 1980; Weldon and Cohen, 1979), cultured myotubes (Burrage and Lentz, 1981), and charged beadinduced aggregate sites (Peng and Cheng, 1982). However, a stratified arrangement with a denser zone $20-50 \mathrm{~nm}$ from the membrane has not been previously described as unique to a developing aggregate site. The stratification seen in the current study was most obvious when myotubes were cut in cross section and was enhanced with tannic acid fixation. It is possible that the deeper zone is a transient structure prominent only at some stage in AChR aggregate formation. Since the deeper, more electron dense zone becomes most apparent only in the latter stage of aggregate formation after the transition from microaggregate to aggregate, it may serve to render the aggregate more stable.

The results of the present study suggest that the formation of AChR aggregates can be initiated prior to the accumulation of basal lamina or the formation of a prominent cytoplasmic density beneath the plasma membrane (see model, Fig. 7). In this regard, Salpeter et al. (1982), using electron-microscopic autoradiography, have reported that the formation of basal lamina and "dense membrane" is correlated with brain extract-induced AChR aggregation occurring after $1 \mathrm{~d}$ or more on rat myotubes. However, they report that a considerable portion of the area of elevated AChR density does not show such specializations. Because aggregate formation is nonsynchronous, it is possible that some sites of elevated AChR density in those studies represented early stages of aggregation (i.e., microaggregates) and were therefore lacking in surface specializations. In addition, Peng and Phelan (1984) have shown the presence of a meshwork of filaments, but the absence of basal lamina and submembrane densities in"presumptive" regions of AChR aggregation under charged beads in contact for $1 \mathrm{hr}$ with Xenopus myocytes. It is possible that this is indicative of a structural stage analogous to that seen at microaggregate sites in the present study. Conversely, Burrage and Lentz (1981), using HRP-BTX mapping, have found submembrane densities and extracellular matrix material at all observed patches of elevated AChR density in developing chick myotubes. It is possible that the experimental conditions favored the detection of more mature aggregates over an earlier stage (i.e., microaggregates) because of the relatively low AChR density and transient nature of microaggregates. Clearly, additional work will be needed to define more precisely the sequence of structural changes associated with AChR aggregation in different experimental systems.

\section{References}

Anderson, M. J., and D. M. Fambrough (1983) Aggregates of acetylcholine receptors are associated with plaques of basal lamina heparan sulfate proteoglycan on the surface of skeletal muscle fibers. $\mathrm{J}$. Cell Biol. 97: 1396-1411.

Anderson, M. J., F. G. Klier, and K. E. Tanguay (1984) Acetylcholine receptor aggregation parallels the deposition of a basal lamina proteoglycan during development of the neuromuscular junction. J. Cell Biol. 99: 1769-1784.

Bennett, M. R., and A. G. Pettigrew (1974) The formation of synapses in striated muscle during development. J. Physiol. (Lond.). 241: 515545 .

Bloch, R. J., and Z. W. Hall (1983) Cytoskeletal components of the vertebrate neuromuscular junction: Vinculin, $\alpha$-actinin, and filamin. J. Cell Biol. 97: 217-223.

Brown, S. S., H. L. Malinoff, and M. S. Wicha (1983) Connectin: Cell surface protein that binds both laminin and actin. Proc. Natl. Acad. Sci. USA 80: 5927-5930.

Burrage, T. G., and T. Lentz (1981) Ultrastructural characterization of surface specialization containing high-density acetylcholine receptors on embryonic chick myotubes in vivo and in vitro. Dev. Biol. 85: 267-286.

Cohen, S. A., and D. W. Pumplin (1979) Clusters of intramembrane particles associated with binding sites of $\alpha$-bungarotoxin in cultured chick myotubes. J. Cell Biol. 82: 494-516.

Coteaux, R. (1955) Localization of cholinesterase at neuromuscular junctions. Int. Dev. Cytol. 4: 335-375.

Couteaux, M. R., and M. Pecot-Dechavassine (1968) Particularités structurales du sarcoplasme sous-neural. C. R. Acad. Sci. [D] (Paris) 266: 8-10.

Daniels, M. P., and Z. Vogel (1975) Immunoperoxidase staining of $\alpha$-bungarotoxin binding sites in muscle endplates shows distribution of acetylcholine receptors. Nature 254: 339-341.

Daniels, M. P., M. Vigny, P. Sonderegger, II. C. Bauer, and Z. Vogel (1984) Association of laminin and other basement membrane components with regions of high acetylcholine receptor density on cultured myotubes. Int. J. Dev. Neurosci. 2: 87-99.

Ellisman, M. H., J. E. Rash, L. A. Staehelin, and K. R. Porter (1976) Studies of excitable membranes. II. A comparison of specialization at neuromuscular junctions and nonjunctional sarcolemmas of mammalian fast and slow twitch muscle fibers. J. Cell Biol. 68: 752-774.

Fertuck, H. C., and M. M. Salpeter (1974) Localization of acetylcholine receptors by ${ }^{125}$ I-labeled alpha-bungarotoxin binding at mouse motor endplates. Proc. Natl. Acad. Sci. USA 71: 1376-1378.

Fertuck, H. C., and M. M. Salpeter (1976) Quantification of junctional and extrajunctional acetylcholine receptors by electron microscopic autoradiography after ${ }^{125} \mathrm{I}$-alpha-bungarotoxin binding at mouse motor endplate. J. Cell Biol. 69: 144-158.

Froehner, S. C., V. Gulbrandson, C. Hyman, A. Y. Jeng, R. R. Neubig, and J. B. Cohen (1981) Immunofluorescence localization at the mammalian neuromuscular junction of $\mathrm{M}_{\mathrm{r}} 43,000$ protein of Torpedo postsynaptic membranes. Proc. Natl. Acad. Sci. USA 78: 5230-5234.

Gulley, R. L., and T. S. Reese (1981) Cytoskeletal organization at the postsynaptic complex. J. Cell Biol. 91: 298-302.

Hall, Z. W., B. W. Lubit, and J. H. Schwartz (1981) Cytoplasmic actin in postsynaptic structures at the neuromuscular junction. J. Cell Biol. 90: 789-792.

Hay, E. D. (1982) Extracellular matrix. J. Cell Biol. 91 (Suppl. 3, Pt. 2): $205 \mathrm{~s}-223 \mathrm{~s}$.

Hirokawa, N., and J. E. Heuser (1982) Internal and external differentiation of the postsynaptic membrane at the neuromuscular junction. J. Neurocytol. 11: 487-510.

Jacob, M., and T. L. Lentz (1979) Localization of acetylcholine receptors by means of horseradish peroxidase- $\alpha$-bungarotoxin during formation and development of the neuromuscular junction in the chick embryo. J. Cell Biol. 82: 195-211.

Kalcheim, C., Z. Vogel, and D. Duksin (1982) Embryonic brain extract induces collagen biosynthesis in cultured muscle cells: Involvement in acetylcholine receptor aggregation. Proc. Natl. Acad. Sci. USA 79: 3077-3081.

Karnovsky, M. J. (1967) The ultrastructural basis of capillary permeability studied with peroxidase as a tracer. J. Cell Biol. 35: 213 .

Kelly, A. M., and S. I. Zacks (1969) The fine structure of motor endplate morphogenesis. J. Cell Biol. 42: 154-169.

Landis, D. M. D., and T. R. Reese (1983) Cytoplasmic organization in cerebellar dendritic spines. J. Ccll Biol. 9: 1169-1 178.

Nakajima, Y., Y. Kidokoro, and F. G. Klier (1980) The development of functional neuromuscular junctions in vitro: An ultrastructural and physiological study. Dev. Biol. 77: 52-72.

Olek, A. J., P. A. Pudimat, and M. P. Daniels (1983) Direct observation of the rapid aggregation of acetylcholine receptors on identified cultured myotubes after exposure to embryonic brain extract. Cell 34 : 255-264.

Peng, H. B., and P. C. Cheng (1982) Formation of postsynaptic specializations induced by latex beads in cultured muscle cells. J. Neurosci. 2 : $1760-1774$. 
Peng, H. B., and K. A. Phelan (1984) Early cytoplasmic specializations at the presumptive acetylcholine receptor cluster: A meshwork of thin filaments. J. Cell Biol. 99: 344-349.

Ravdin, P., and D. Axelrod (1977) Fluorescent tetramethyl-rhodamine derivatives of $\alpha$-bungarotoxin: Preparation, separation, and characterization. Anal. Biochem. 80: 585-592.

Salpeter, M. M., S. Spanton, K. Holley, and T. R. Podleski (1982) Brain extract causes acetylcholine receptor redistribution which mimics some early events at developing neuromuscular junctions. J. Cell Biol. 93: 417-425.

Sanes, J. R. (1982) Laminin, fibronectin, and collagen in synaptic and extrasynaptic portions of muscle fiber basement membrane. J. Cell Biol. 93: 442-451.

Sanes, J. R. (1983) Roles of extracellular matrix in neural development. Annu. Rev. Physiol. 45: 581-600.

Sanes, J. R., and Z. W. Hall (1979) Antibodies that bind specifically to synaptic sites on muscle fiber basal lamina. J. Cell Biol. 83: 357370.

Sanes, J. R., D. H. Feldman, J. M. Cheney, and J. C. Iawrence (1984) Brain extract induces synaptic characteristics in the basal lamina of cultured myotubes. J. Neurosci. 4: 464-473.

Schaffner, A. E., and M. P. Daniels (1982) Conditioned medium from cultures of embryonic neurons contains a high molecular weight factor which induces acetylcholine receptor aggregation on cultured myotubes. J. Neurosci. 2: 623-632.

Vogel, Z., M. Towbin, and M. P. Daniels (1979) Alpha-bungarotoxinhorseradish peroxidase conjugate: Preparation, properties and utilization for the histochemical detection of acetylcholine receptors. J. Histochem. Cytochem. 27: 846-851.

Weldon, P. R., and M. W. Cohen (1979) Development of synaptic ultrastructure at neuromuscular contacts in an amphibian cell culture system. J. Neurocytol. 8: 239-259. 